\title{
SIMULASI PENGATURAN KECEPATAN MOTOR INDUKSI 3 PHASA DENGAN DIRECT TORQUE CONTROL MENGGUNAKAN MATLAB
}

\author{
Ulfatun Khasanah $^{[1]}$, Supari, ${ }^{[2]}$, Sri Heranurweni ${ }^{[3]}$. \\ 1,2,3 Jurusan Teknik Elektro, Fakultas Teknik, Universitas Semarang \\ email : Vaa_ryo@yahoo.com, supari@usm.ac.id, heranur@usm.ac.id
}

\begin{abstract}
Abstrak - Motor induksi banyak dipergunakan dalam dunia industri karena memiliki banyak kelebihan, diantaranya konstruksi yang sangat sederhana dan kuat, harganya murah, mempunyai effisiensi yang tinggi, power factor cukup baik, dan perawatannya lebih mudah. Disamping kelebihan motor induksi juga memiliki kelemahan, salah satu kelemahan dari motor induksi adalah tidak mampu mempertahankan kecepatannya dengan konstan bila terjadi perubahan beban. Apabila terjadi perubahan beban maka kecepatan motor induksi akan menurun. Salah satu metode pengaturan kecepatan motor induksi yang dikembangkan selain kontrol vektor adalah metode Direct Torque Control (DTC). Teknik kontrol DTC memungkinkan pengaturan fluks dan torsi secara langsung dan terpisah serta dapat dilakukan tanpa menggunakan sensor kecepatan. Estimasi putaran rotor, torsi dan fluks dilakukan oleh DTC yang diberi masukan tegangan dan arus stator. Untuk mencapai fluks dan torsi yang dikehendaki digunakan estimasi sebagai umpan balik pada sistem kontrol. Pada tugas akhir ini akan disimulasikan pengaturan kecepatan motor induksi dengan metode DTC menggunakan Matlab.

Hasil yang diperoleh melalui simulasi menunjukan lama waktu untuk mencapai kecepatan referensi untuk kecepatan 500rpm dan $1000 \mathrm{rpm}$ adalah berkisar 0,5 detik.
\end{abstract}

Kata kunci : Motor Induksi, Direct Torque Control, Matlab.

Abstract - Induction motors are widely used in the industrial world because they have many advantages, including construction that is very simple and strong, cheap, has high efficiency, quite good power factor, and maintenance is easier. Besides the advantages of induction motors also have weaknesses, one of the disadvantages of an induction motor is not being able to maintain its speed constantly if there is a change in load. If there is a change in load, the speed of the induction motor will decrease. One method of regulating the speed of an induction motor developed in addition to vector control is the Direct Torque Control (DTC) method. The DTC control technique allows direct and separate flux and torque settings and can be done without using a speed sensor. The estimated rotor rotation, torque and flux is carried out by the DTC which is inputted with stator voltage and current. To achieve the desired flux and torque estimation is used as feedback on the control system. In this final assignment, the speed regulation of the induction motor will be simulated using the DTC method using Matlab.

The results obtained through the simulation show the length of time to reach the reference speed for speeds of 500rpm and $1000 \mathrm{rpm}$ is around 0.5 seconds.

Keywords : Induction motor, Direct Torque Control, Matlab.

\section{PENDAHULUAN}

Saat ini kebutuhan akan alat produksi yang tepat sangat diperlukan untuk dapat meningkatkan efisiensi waktu, dan biaya. Motor induksi adalah motor yang paling banyak digunakan. Salah satu keuntungan utamanya adalah motor induksi tidak membutuhkan hubungan elektrik antara stator dengan rotor motor, oleh karena itu motor induksi tidak membutuhkan brush dan komutator, sehingga tidak membutuhkan perawatan yang rutin. Motor induksi memiliki konstruksi yang sangat sederhana dan kuat, harganya murah, mempunyai effisiensi yang tinggi, power factor cukup baik, dan perawatannya lebih mudah. Salah satu kelemahan dari motor induksi adalah tidak mampu mempertahankan kecepatannya dengan konstan bila terjadi perubahan beban. Apabila terjadi perubahan beban maka kecepatan motor induksi akan menurun. Salah satu metode yang digunakan untuk kontrol motor induksi adalah metode Direct Torque Control (DTC).

\section{TINJAUAN PUSTAKA}

\subsection{DIRECT TORQUE CONTROL (DTC)}

Direct Torque Control pertama kali dikembangkan oleh Takashi dan Noguchi tahun 1986. Dasar dari metode DTC adalah perubahan torsi sebanding dengan slip antara fluks stator dan fluks rotor pada kondisi fluks bocor stator tetap. Oleh karena itu, pada keadaan perubahan yang cepat fluks rotor cenderung tidak berubah. Perubahan cepat dari torsi elektromagnetik dapat dihasilkan dari putaran fluks stator, sebagai arah torsi. Dengan kata lain fluks stator dapat seketika mempercepat atau memperlambat dengan menggunakan vektor tegangan stator yang sesuai. Torsi dan fluks dikontrol bersama-sama dengan pengaturan langsung dari tegangan stator, dari error respon torsi dan fluks. Untuk menentukan putaran motor dapat digunakan persamaan rangkaian dan arus motor diukur pada reference frame, sehingga persamaan tegangan stator dalam kerangka stator referensi adalah :

$$
\begin{aligned}
& \bar{v}_{\mathrm{s}}=\mathrm{R}_{\mathrm{s}} \bar{I}_{\mathrm{s}}+\frac{d \overline{\lambda_{s}}}{d t} \\
& \bar{\lambda}_{\mathrm{s}}=\int\left(\overline{v S}-\mathrm{R}_{\mathrm{s}} \bar{I}_{\mathrm{s}}\right) \mathrm{dt}
\end{aligned}
$$

Dengan demikian fluks linkages dalam koordinat stator reference frames dihitung berdasarkan

$$
\begin{aligned}
& \lambda_{\mathrm{qs}}=\int(V q s-R s I q s) d t \\
& \lambda_{\mathrm{ds}}=\int(V d s-R s I d s) d t
\end{aligned}
$$




$$
\begin{aligned}
& \lambda_{s}=\sqrt{(\lambda q s)^{2}+(\lambda q s)^{2}}<\Phi f s \\
& \Phi f_{s}=\tan ^{-1}\left[\frac{\lambda q s}{\lambda d s}\right]
\end{aligned}
$$

Persamaan torsi elektromagnetik adalah :

$$
\mathrm{Te}=\frac{3}{2} \frac{P}{2}\left(\mathrm{i}_{\mathrm{qs}} \lambda_{\mathrm{ds}}-\mathrm{i}_{\mathrm{ds}} \lambda_{\mathrm{qs}}\right)
$$

Frekuensi listrik dihitung dengan mendifferensialkan sudut vektor fluks rotor yaitu :

$$
\omega_{\mathrm{e}}=\frac{\lambda q s \lambda d s-\lambda d s \lambda q s}{\lambda^{2} s}
$$

Persamaan kecepatan rotor adalah :

$$
\omega_{\mathrm{r}}=\mathrm{P}\left(\omega \mathrm{e}-\operatorname{Rr} \frac{T e}{\lambda r^{2}}\right)
$$

Dengan $: \bar{v}_{\mathrm{s}}=$ vektor tegangan stator

$$
\begin{aligned}
& \bar{I}_{\mathrm{s}}=\text { vektor arus stator } \\
& \mathrm{R}_{\mathrm{s}}=\text { tahanan stator } \\
& \bar{\lambda}_{\mathrm{s}}=\text { vektor fluks stator }
\end{aligned}
$$

Skema DTC dapat dilihat pada gambar 1.

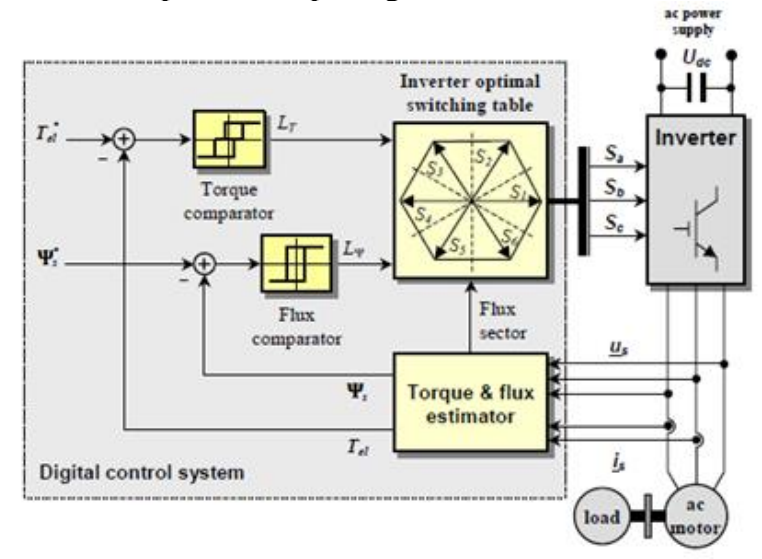

Gambar 1 . Skema DTC

\subsection{Komparator Histerisis}

Pada metode DTC, controller yang digunakan untuk mengatur kesalahan fluks dan torsi pada daerah histerisisnya agar sesuai dengan fluks referensi dan torsi referensi menggunakan komparator hysteresis. Pada kesalahan fluks dihasilkan dua nilai histerisis yaitu -1 atau 1 dan pada kesalahan torsi dihasilkan tiga nilai histerisis yaitu -1,0 dan 1 .

Nilai kesalahan fluks dan torsi didapatkan dari persamaan :

$$
\begin{aligned}
& \Delta_{\text {te }}=\mathrm{T}_{\text {ref }}=\mathrm{T}_{\text {est }} \\
& \Delta \psi^{\mathrm{s}}=\psi_{\text {ref }}^{\mathrm{s}}-\psi^{\mathrm{s}} \text { est }
\end{aligned}
$$

\subsection{Switching Table}

Switching table berisi dua tabel yang memilih vektor tegangan tertentu sesuai dengan output dari flux dan torque hysterisis pembanding. Algoritma pemilihan vektor tegangan inverter pada DTC untuk diterapkan pada motor induksi didasarkan pada nilai dari fluks dan torsi histerisis, serta nilai dari sektor fluks stator. Adapun aturan pemilihan tegangan pada switching table seperti ditunjukan pada tabel 1.
Tabel 1. Switching table

\begin{tabular}{|c|c|c|c|c|c|c|c|}
\hline S. & S & \multicolumn{6}{|c|}{$\mathrm{S}$} \\
\hline & & $\begin{array}{c}\text { Sektor } \\
1\end{array}$ & $\begin{array}{c}\text { Sektor } \\
2\end{array}$ & $\begin{array}{c}\text { Sektor } \\
3\end{array}$ & $\begin{array}{c}\text { Sektor } \\
4\end{array}$ & $\begin{array}{c}\text { Sektor } \\
5\end{array}$ & $\begin{array}{c}\text { Sektor } \\
6\end{array}$ \\
\hline 1 & 1 & $\mathrm{~V}_{2}(110)$ & $\mathrm{V}_{3}(010)$ & $\mathrm{V}_{4}(011)$ & $\mathrm{V}_{5}(001)$ & $\mathrm{V}_{6}(101)$ & $\mathrm{V}_{1}(100)$ \\
\hline 1 & 0 & $\mathrm{~V}_{7}(111)$ & $\mathrm{V}_{0}(000)$ & $\mathrm{V}_{7}(111)$ & $\mathrm{V}_{0}(000)$ & $\mathrm{V}_{7}(111)$ & $\mathrm{V}_{0}(000)$ \\
\hline 1 & -1 & $\mathrm{~V}_{6}(101)$ & $\mathrm{V}_{1}(100)$ & $\mathrm{V}_{2}(110)$ & $\mathrm{V}_{3}(010)$ & $\mathrm{V}_{4}(011)$ & $\mathrm{V}_{5}(001)$ \\
\hline 0 & 1 & $\mathrm{~V}_{3}(010)$ & $\mathrm{V}_{4}(011)$ & $\mathrm{V}_{5}(001)$ & $\mathrm{V}_{6}(101)$ & $\mathrm{V}_{1}(100)$ & $\mathrm{V}_{2}(110)$ \\
\hline 0 & 0 & $\mathrm{~V}_{0}(000)$ & $\mathrm{V}_{7}(111)$ & $\mathrm{V}_{0}(000)$ & $\mathrm{V}_{7}(111)$ & $\mathrm{V}_{0}(000)$ & $\mathrm{V}_{7}(111)$ \\
\hline 0 & -1 & $\mathrm{~V}_{5}(001)$ & $\mathrm{V}_{6}(101)$ & $\mathrm{V}_{1}(100)$ & $\mathrm{V}_{2}(110)$ & $\mathrm{V}_{3}(010)$ & $\mathrm{V}_{4}(011)$ \\
\hline
\end{tabular}

Adapun nilai sektor fluks stator didapat dari :

$\alpha=<\psi_{\mathrm{s}}=\tan ^{-1} \frac{\psi q s}{\psi d s}$

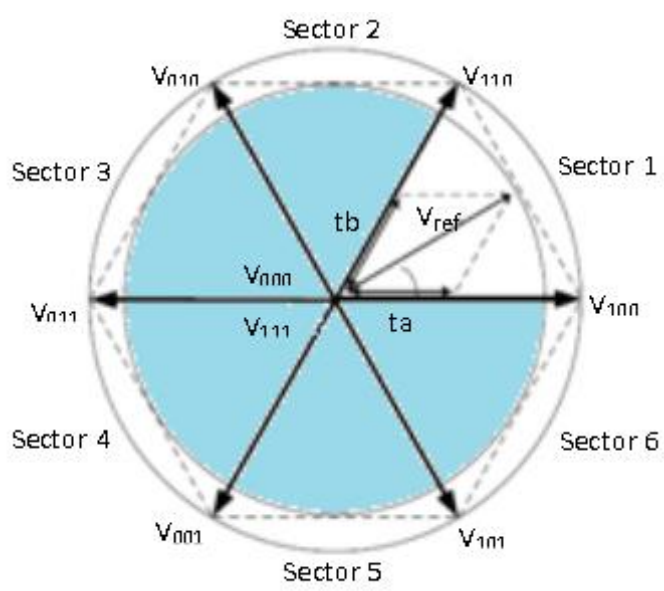

Gambar 2. Vektor Tegangan Inverter dan Sektor Fluks

\section{PERANCANGAN SISTEM}

\subsection{Flowchart Perancangan Simulasi}

Flowchart dibuat agar apa yang dilakukan sesuai dengan tahapan perancangan simulasi. Flowchart simulasi pengaturan kecepatan motor induksi 3 phasa dengan direct torque control menggunakan matlab dapat dilihat pada gambar 3 . 


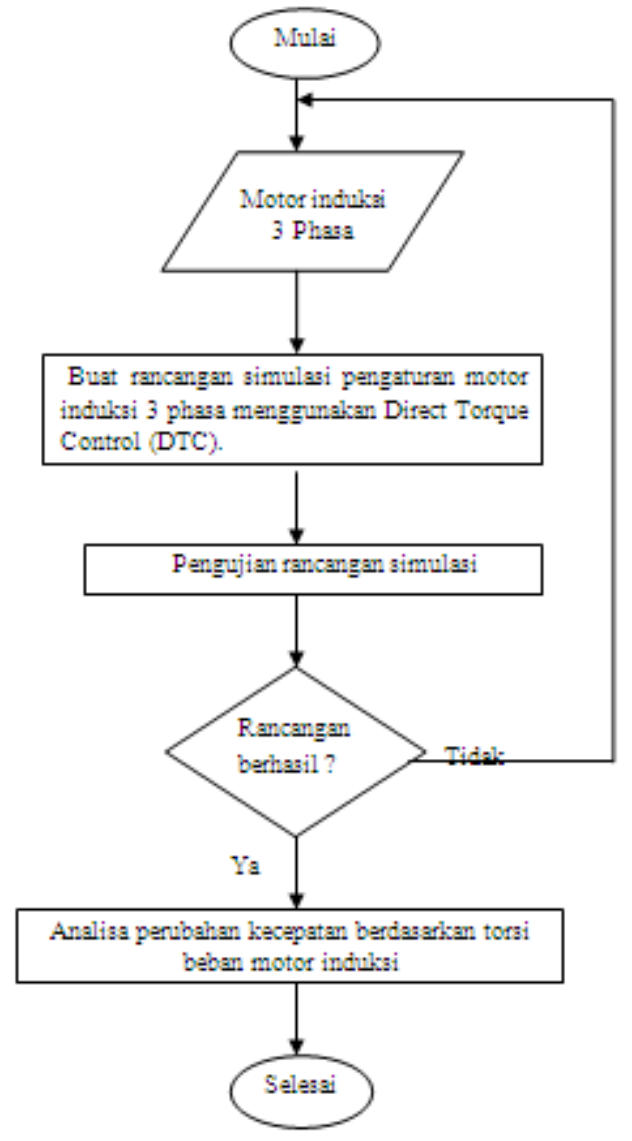

Gambar 3. Flowchart Simulasi

Tabel 2. Tabel Spesifikasi Motor Induksi

\begin{tabular}{|c|l|c|}
\hline No. & \multicolumn{1}{|c|}{ Spesifikasi } & $3 \mathrm{HP}$ \\
\hline 1 & Tegangan(Volt) & $220 \mathrm{~V} / 380 \mathrm{~V}$ \\
\hline 2 & Frekuensi(Hz) & $50 \mathrm{~Hz}$ \\
\hline 3 & Daya (HP) & $3 \mathrm{HP}$ \\
\hline 4 & Kecepatan(Rpm) & $1430 \mathrm{rpm}$ \\
\hline 5 & Jumlah Pasang Kutub & 2 \\
\hline 6 & Tahanan Stator (Ohm) & 0,435 \\
\hline 7 & Tahanan Rotor(Ohm) & 0,816 \\
\hline 8 & Induktansi Stator dan Rotor (H) & 0.002 \\
\hline 9 & Induktansi Magnetik(H) & 0.069 \\
\hline 10 & Momen Inersia (kg.m $\left.{ }^{2}\right)$ & 0,089 \\
\hline 11 & Koefisien Redaman (N.m.s) & 0,02 \\
\hline
\end{tabular}

Motor induksi yang digunakan dalam tugas akhir ini adalah motor induksi jenis rotor sangkar (squirrel-cage) hubungan bintang (Y), dimana dari motor induksi ini dapat diketahui besar tegangan atau arus tiap phasanya. Keluaran yang dihasilkan dari motor induksi tiga phasa ini terdiri dari sistem elektrik yaitu nilai fluks stator, torsi elektromagnetis dan sistem mekanis yaitu kecepatan putaran rotor. Perancangan simulasi DTC ini menggunakan motor induksi tenaga 3 HP dengan spesifikasi yang ditunjukan pada tabel 2.

Berdasarkan parameter motor induksi yang ada diatas, maka dapat ditentukan nilai kecepatan stator sebagai berikut

$$
\begin{aligned}
& \mathrm{N}_{\mathrm{s}}=\frac{60 . f}{p} \\
& \mathrm{~N}_{\mathrm{s}}=\frac{600.50}{2} \\
& \mathrm{~N}_{\mathrm{s}}=1500 \mathrm{rpm}
\end{aligned}
$$

\subsection{PERANCANGAN DTC pada PROGRAM MATLAB}

Model simulasi Direct Torque Control (DTC) dikembangkan menggunakan program simulasi Matlab, masukan yang digunakan adalah fluks dan torsi acuan. Cara kerja DTC adalah dengan mempertahankan keluaran fluks dan torsi agar sesuai dengan referensi yang diberikan. Adapun bagian bagian yang dirancang pada metode DTC ini adalah komparator, estimator, sektor sudut fluks stator, dan switching table dengan menggunakan persamaan-persamaan dan algoritma. Rangkaian simulasi DTC dapat dilihat di gambar 4.

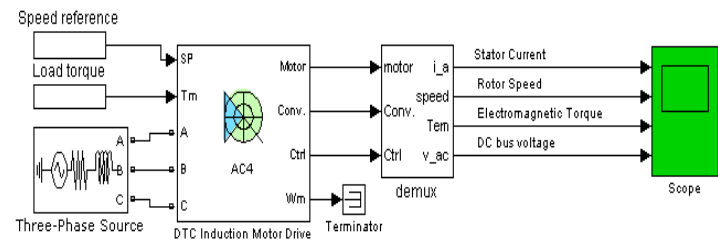

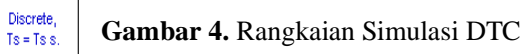

\section{IV.SIMULASI DAN ANALISA}

Simulasi pengaturan kecepatan putaran motor induksi tiga phasa di lakukan dengan menggunakan Matlab. Rangkaian simulasi ditunjukan pada gambar 4. Motor induksi yang digunakan adalah motor induksi 3phasa dengan daya $3 \mathrm{HP}$. Masukan kecepatan referensi yang diberikan adalah 500rpm, kemudian dinaikkan menjadi $1000 \mathrm{rpm}$ pada saat $\mathrm{t}=1$ detik. Simulasi dilakukan selama 3 detik untuk kondisi tanpa torsi beban dan kondisi dengan torsi beban sebesar $5 \mathrm{Nm}$ dan 10Nm. Hasil simulasi untuk kondisi tanpa torsi beban ditunjukan pada gambar 5. Kondisi dengan torsi beban sebesar $5 \mathrm{Nm}$ ditunjukan pada gambar 6, dan kondisi dengan torsi beban sebesar 10Nm ditunjukan pada gambar 7 .

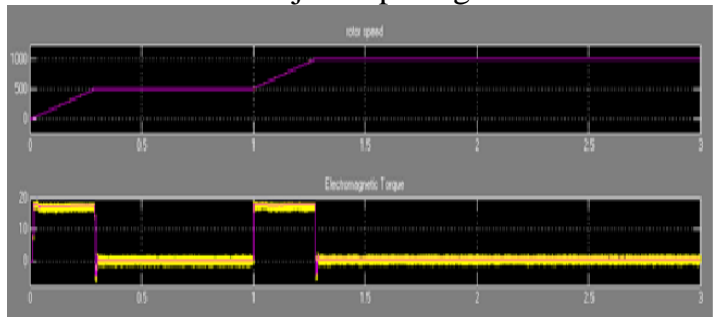

Gambar 5. Grafik Hasil Simulasi tanpa Torsi Beban 


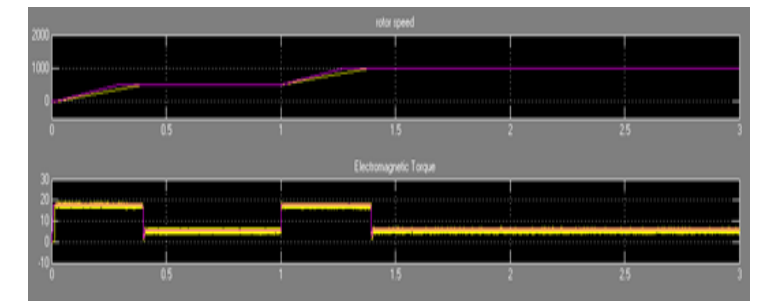

Gambar 6. Grafik Hasil Simulasi dengan Torsi Beban Sebesar 5Nm

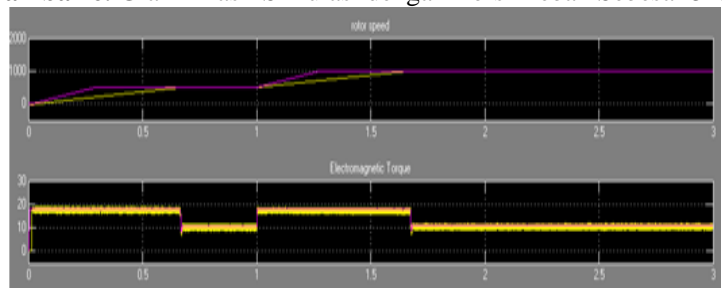

Gambar 7. Grafik Hasil Simulasi dengan Torsi beban sebesar 10Nm.

Dari hasil simulasi pengaturan kecepatan motor induksi dengan direct torque control untuk kecepatan referensi 500 rpm dan 1000rpm terlihat bahwa untuk kondisi torsi tanpa beban motor mampu mencapai kecepatan referensi dalam waktu 0,25 detik. Pada saat torsi beban sebesar 5Nm, motor mampu mencapai kecepatan referensi dalam waktu 0,38, dan pada saat torsi beban sebesar $10 \mathrm{Nm}$, motor mampu mencapai kecepatan referensi dalam waktu 0,64 detik untuk kecepatan referensi 500rpm dan 0,65 detik untuk kecepatan referensi 1000rpm. Perbandingan respon kecepatan dapat dilihat pada tabel 3.

Tabel 3. Respon Kecepatan

\begin{tabular}{|l|c|c|c|}
\hline \multirow{2}{*}{ Parameter } & \multicolumn{3}{|c|}{ Torsi Beban } \\
\cline { 2 - 4 } & $0 \mathrm{Nm}$ & $\mathbf{5 N m}$ & $10 \mathrm{Nm}$ \\
\hline $\begin{array}{l}\text { Lama Mencapai Kecepatan } \\
\text { Referensi 500Rpm(s) }\end{array}$ & 0,25 & 0,38 & 0,64 \\
\hline $\begin{array}{l}\text { Lama Mencapai Kecepatan Referensi } \\
\text { 1000Rpm(s) }\end{array}$ & 0,25 & 0,38 & 0,65 \\
\hline
\end{tabular}

\section{KESIMPULAN}

1. Pengaturan kecepatan motor induksi dengan metode Direct Torque Control (DTC) mempunyai respon dinamik yang tinggi, hal ini dapat dilihat dari kecepatan aktual dalam mengikuti kecepatan referensi.

2. Respon torsi dari hasil simulasi memperlihatkan bahwa respon torsi yang dihasilkan dapat mengikuti torsi acuan yang diberikan, ketika diberi torsi beban $5 \mathrm{Nm}$, torsi beban $10 \mathrm{Nm}$, maupun tanpa torsi.

3. Respon kecepatan aktual motor induksi dipengaruhi oleh beban. Semakin besar beban yang diberikan akan mengakibatkan respon kecepatan aktual untuk mengikuti kecepatan referensi semakin lambat.

\section{DAFTAR PUSTAKA}

ABB Technical Guide "Direct Torque Control". Rev C 6.6.2001.

D.Casadei,G.Serra,A.Tani,and L.Zarri,"Assessment of Direct Torque Control for Induction Motor Drives", Buletin of the Polish Academy of Science

Tech.Sciences, vol.54.No.3,2006.

Dharmaprakash R, Joseph Henry, "Switching Table Based 2 Level Inverter and 3 Level Diode Clamped Inverter",University Hyedrabad,India, Vol.60 No.2.2014.

Eugene C.Lister,Ir. Drs.Hanapi Gunawan, "Mesin dan Rangkaian Listrik”,Penerbit Erlangga,1997.

Inc."ReferenceFrame Conversions". Analog Device 2002.

Kadjoudj Mohamed, Noureddine Golea, Med Hachemi,"Voltage Switching Tables for Direct Torque Control of PMSM Drive".U.P.B.Sci.Bull,Series C,vol.69,No.3.2007.

M.N.Cirstea,A.Dinu,J.G.Khor,M.Mc Cormick,"Neural and Fuzzy Logic Control of Drives and Power System".Newnes, 2002.

Prasad V.H,"2 Space Vektor Modulation for Three Leg Voltage Source Inverters",1997.

R.J. Lee,P.Pillay,R.G. Harley,'DQ Reference Frames for the Simulation of Induction Motors".Elseiver Sequoia, 1984.

Toufouti Riad, Salima Meziane, Hocine Benalla,"Direct Torque Control Strategy of Induction Motors", Acta Electrotechnica et Informatica No.1,Vol7,2007.

Wahab Abdul H.F dan Sanusi H,"Simulink Model of Direct Torque Control of Induction Machine", American Journal of Applied Science,2008.

Zuhal,Zhanggischan."Prinsip Dasar Elektroteknik”, Penerbit Gramedia Pustaka Mas,2004. 